\title{
ON BRINE DRAINAGE CHANNELS OF YOUNG SEA ICE
}

\author{
by
}

\section{MASAAKI WAKATSUCHI}

Institute of Low Temperature Science, Hokkaido University, Sapporo, Japan 060

TAKashi SaIto

Koshimizu High School, Koshimizu, Hokkaido, Japan 099

\begin{abstract}
This paper describes characteristic features of brine channels observed both macroscopically and microscopically using samples of natural sea ice Systematic observations of brine channels, including the effects of ice growth rate and ice thickness, provide knowledge of their spatial distribution in young sea ice.
\end{abstract}

\section{INTRODUCTION}

Brine drainage channels are characteristic of sea ice, generally taking the form of a tree; they consist of large vertical tubular structure attended by smaller tributary tubes. When sea ice forms, a portion of brine is mechanically trapped in the ice matrix but a remainder is excluded into the underlying seawater. With a growth of ice sheet numerous brine pockets form between ice plates and between ice crystals (grains), some joining to form brine channels as drainage paths back into the seawater.

Since their discovery by Bennington (1963), the spatial density of brine channels has been examined, using samples of natural sea ice, by several investigators (Bennington 1967; Lake and Lewis 1970; Martin 1979). However, reports on spatial density are arbitrary because of the use of different ice samples without reference to growth history. Saito and Ono (1980) have therefore examined spatial density of brine channels as a function of ice growth rate, using samples of $\mathrm{NaCl}$ ice. According to their laboratory results, spatial density increases with increasing ice growth rate, at least for the samples of thin ice (up to $10 \mathrm{~cm}$ thick) used.

The present study aims to observe, using the samples of natural sea ice with known growth histories, morphological characteristics and spatial distribution of brine channels, both macroscopically and microscopically.

\section{OBSERVATION METHOD}

Two kinds of ice samples were obtained from salty lake Saroma, Hokkaido, each February from 1982 to 1984. The first sample was a fast ice sheet about $30 \mathrm{~cm}$ thick. Another sample was taken from newly formed sea ice in an artificial test pool with a dimension of about $2 \mathrm{~m} \times 2 \mathrm{~m}$ in area, made by removing ice blocks from the fast ice sheet: new ice formed when the open water surface was exposed to cold air. The thickness of new ice which formed overnight ranged from about $3 \mathrm{~cm}$ minimum to $6 \mathrm{~cm}$ maximum. The pool was renewed every day, by removing all the sea ice that formed. There new ice samples were used to examine the ice growth rate effect on spatial density of brine channels. Meanwhile, the thickness effect on density was investigated with the samples of thicker fast ice sheet.

Samples $30 \mathrm{~cm} \times 30 \mathrm{~cm}$ in area from the pool were carefully placed on a netted table and left for several hours to drain brine trapped in the channels. By putting the brine-drained ice sample on a black cloth sheet, or more effectively by floating the sample in open water, we could observe clearly the cross-sectional form of individual brine channels.
To observe microscopically the distribution of brine channels in a complex ice crystal structure, we have developed a new technique of taking polarized photographs which shows brine channels as well as grains, lighting the sample through a slit from one side, not from below. An example is shown in Figure 1.

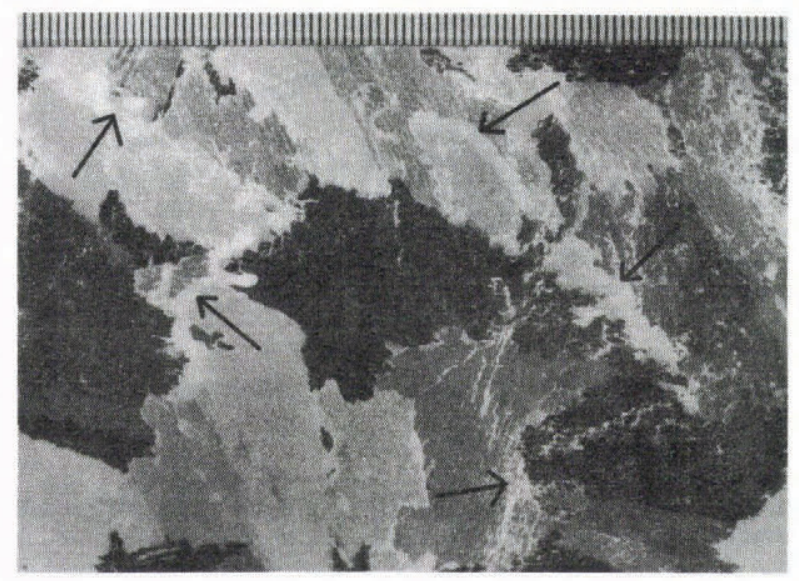

Fig.1. Horizontal section of an ice sample obtained in the pool. Bright parts indicated by arrows are the horizontal section of brine channels. A scale of $1-\mathrm{mm}$ interval is indicated on the upper.

\section{SPATIAL DISTRIBUTION OF BRINE CHANNELS} Microscopic observation.

From numerous photographic analyses we found that brine channels of new ice form frequently in boundary areas where two or more grains intersect, not in contact boundaries between parallel grains or within the grains. However, in samples of thicker ice sheet some brine channels were observed to exist within the interior of grains at lower levels. According to vertical sections of ice samples, a predominant brine channel advances in a straight line toward the growing ice front. Although the brine channels form in the intersecting boundary areas of grains at an initial stage of ice growth, they may subsequently advance vertically, independent of grain orientation.

\section{Large scale observation}

As shown in Figure 2, brine channels in new ice spread homogeneously in space, and are roughly similar in size. To test homogeneity in larger samples an area of $10 \mathrm{~m} \times 10 \mathrm{~m}$ in the fast ice cover was selected as a test site. Ice samples were taken from a network of $3 \mathrm{x}$ 3 stations within the test site. The cross-sectional area of the nine ice samples was about $45 \mathrm{~cm} \times 45 \mathrm{~cm}$. A depth of $7 \mathrm{~cm}$ from the bottom surface of ice samples was selected as a test level for the observation of brine channels. 


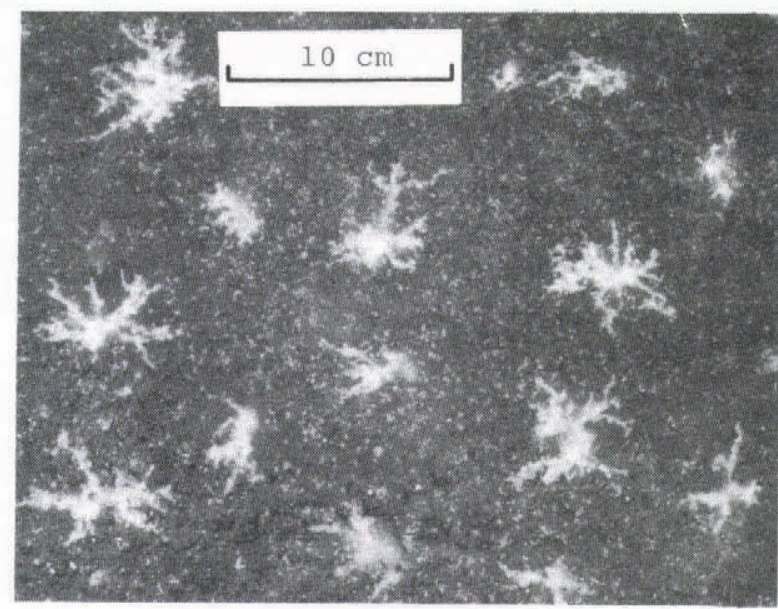

Fig.2. A macroscopic view of the horizontal section of brine channels, each resembling the shape of a bright star.

We found that spatial density of predominant brine channels varied little between ice samples selected: the average density was $2.4 \pm 0.2$ channels $/ 100 \mathrm{~cm}^{2}$, and individual brine channel size was similar throughout. We concluded that the predominant brine channels spread homogeneously in space, at least in young sea ice like the sheet we were studying, which formed under calm natural conditions.

\section{Ice growth rate effect}

The spatial density of brine channels as a function of ice growth rate was examined using samples of new ice (up to $6 \mathrm{~cm}$ thick) obtained in the pool. The only other data available on this subject are laboratory observations at higher growth rates of Saito and Ono (1980) on $\mathrm{NaCl}$ ice. As shown in Figure 3, their results compare reasonably with the present observations in spite of large differences between laboratory and natural conditions. The maximum thickness of two kinds of ice samples shown in Figure 3 is about $10 \mathrm{~cm}$. Hereafter, let us call an ice growing process up to the thickness the initial stage of ice growth.

For ice growth rates between $1 \times 10^{-5}$ and $11 \times$ $10^{-5} \mathrm{~cm} / \mathrm{s}$, spatial densities of predominant brine channels range from about two to about 15 channels/100 $\mathrm{cm}^{2}$ increasing with ice growth rate. As mentioned previously, most brine channel spread in the interesecting boundary areas of grains during the initial stage of ice growth. The interesecting frequency of grains increases with increasing ice growth rate since the average grain size becomes smaller as the ice growth rate increases.

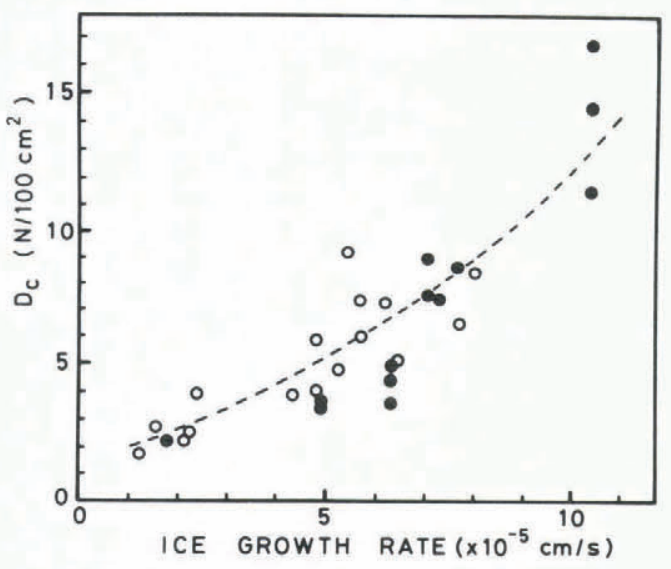

Fig.3. Spatial density $D_{c}$ (channel number per $100 \mathrm{~cm}^{2}$ ) of brine channels vs ice growth rate at the initial stage of ice growth (- after Saito and Ono, 1980).
Therefore, it is suggested that at the initial stage of ice growth the spatial density of brine channels is highly related to the intersecting frequency of grains as a function of ice growth rate.

These observations on samples of relatively thin ice from the pool show that density depended upon the ice growth rate at the initial stage of growth. We will next examine the thickness effect on the density using a sample of thicker fast ice sheet.

\section{THICKNESS EFFECT}

The vertical section of natural thick sea ice is characterized by a series of distinct horizontal lines made of air bubbles. The horizontal lines indicate the growth history of the sea ice; the interval between the horizontal lines corresponds to the amount of ice growth per day, namely, the ice growth rate. For the present fast ice sheet growth rates change variously with depth. Figure 4 shows the morphological features observed at each level with different growth rates.

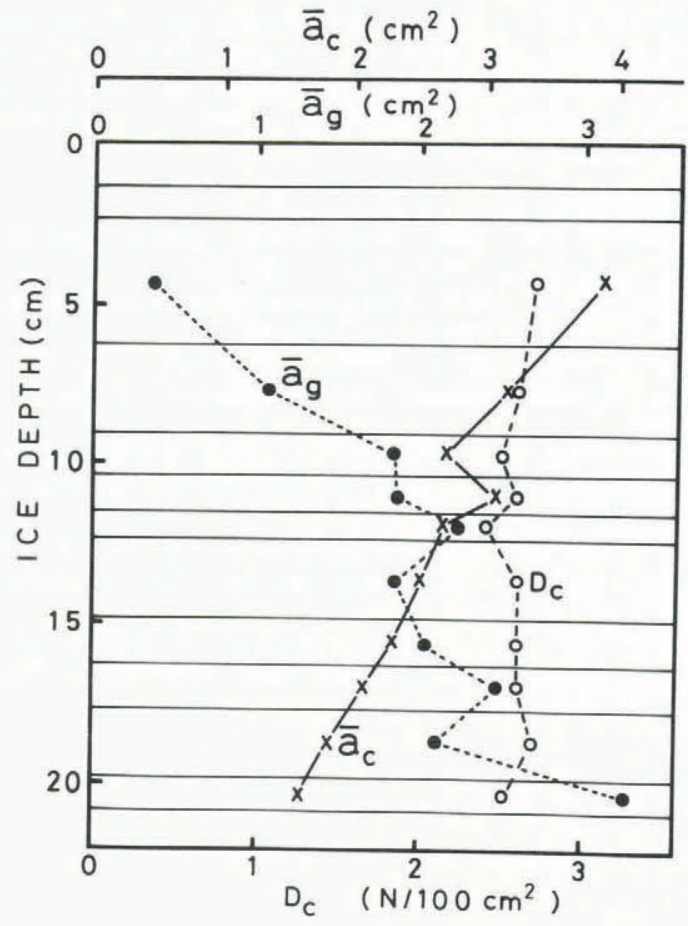

Fig.4. Average grain size $\overline{\mathrm{a}}_{\mathrm{g}}(\bullet)$, average cross-sectional area $\overline{\mathrm{a}}_{\mathrm{c}}(\mathrm{X})$ and spatial density $\mathrm{D}_{\mathrm{c}}(\mathrm{O})$ of brine channels against ice depth. Interval between horizontal lines shows the amount of ice growth per day.

It is well known that the average grain size of sea ice becomes larger with depth and also with decreasing ice growth rate (eg Wakatsuchi 1974). The trends are also recognizable in the present fast ice samples; the grain size generally becomes larger with depth, following the change of ice growth rate at deeper levels. However, spatial density of brine channels is roughly constant in spite of the change of ice growth rate with depth, though the average cross-sectional area of brine channels decreases with depth. Therefore, the strong dependency upon ice growth rate of the spatial density of brine channels, as shown in Figure 3 , may be dominant at the initial stage of growth. In summary, for a thicker sea ice the spatial density of brine channels is approximately determined by the ice growth rate at the initial stage of ice growth, and is maintained during the subsequent ice growth.

\section{CONCLUDING REMARKS}

Morphological characteristics and spatial distribution of brine channels in a young sea ice sheet have been examined systematically: findings obtained are summarized as follows: 
1) Brine channels distribute homogenously in space and their sizes are approximately similar.

2) Spatial density of brine channels at the initial stage of ice growth (up to $10 \mathrm{~cm}$ thick) increases with increasing ice growth rate. The density determined by ice growth rate at the early stage is maintained during subsequent ice growth and changes little with depth, though the cross-sectional area of individual brine channels becomes smaller.

3) At the initial stage of ice growth, most brine channels form in the intersecting boundary areas of grains. Both the spatial density of brine channels and the intersecting frequency of grains increase with increasing ice growth rate, suggesting a high correlation between them as a function of ice growth rate However, as sea ice thickens, the brine channels advance vertically, being independent of grains; hence, some brine channels are present in the interior of individual grain at deeper levels.

\section{ACKNOWLEDGEMENTS}

The authors thank $T$ Kawamura and $T$ Takizawa for their assistance with field work. This study was partly supported by the Grant-in-Aid for Fundamental Scientific Research (56460037) from the Japanese Ministry of Education.

\section{REFERENCES}

Bennington K O 1963 Some crystal growth features of sea ice. Journal of Glaciology 4: 669-688

Bennington K O 1967 Desalinationfeatures in natural sea ice. Journal of Glaciology 6: 845-857

Lake R A, Lewis E L 1970 Salt rejection by sea ice during growth. Journal of Geophysical Research 75: 583-597

Martin S 1979 A field study of brine drainage and oil entrainment in first year sea ice. Journal of Glaciology 22: $473-502$

Saito T, Ono N 1980 Percolation of sea ice. II. Brine drainage channels in young sea ice. Low Temperature Science A39: 127-132

Wakatsuchi M 1974 Experiments on the growth of sea ice and the rejection of brine. Low Temperature Science A32: $195-205$ 